Endophyte-enhanced phytoremediation of DDE-contaminated using Cucurbita pepo: A field trial

Peer-reviewed author version

EEVERS, Nele; Hawthorne, J. R.; White, J. C.; VANGRONSVELD, Jaco \& WEYENS, Nele (2018) Endophyte-enhanced phytoremediation of DDE-contaminated using Cucurbita pepo: A field trial. In: INTERNATIONAL JOURNAL OF PHYTOREMEDIATION, 20(4), p. 301-310.

DOI: $10.1080 / 15226514.2017 .1377150$

Handle: http://hdl.handle.net/1942/26258 
8

9

\section{Endophyte-enhanced phytoremediation of DDE-contaminated using Cucurbita pepo: a field trial}

Eevers N. ${ }^{1}$, Hawthorne J.R. ${ }^{2}$, White J.C. ${ }^{2}$, Vangronsveld J. ${ }^{1 *}$, Weyens N. ${ }^{1}$ *Corresponding author E-mail jaco.vangronsveld@uhasselt.be Tel +32 11268331 Fax +3211268301

${ }^{1}$ Hasselt University, Centre for Environmental Sciences, Agoralaan Building D, 3590 Diepenbeek, Belgium

${ }^{2}$ Connecticut Agricultural Experiment Station, Dept of Analytical Chemistry, 123 Huntington Street, CT 06511 New Haven, USA

Full names and email addresses of all authors:

Eevers Nele; nele.eevers@uhasselt.be

Hawthorne Joseph R.; joseph.hawthorne@ct.gov

White Jason C.; jason.white@ ct.gov

Vangronsveld Jaco; jaco.vangronsveld@ uhasselt.be

Weyens Nele; nele.weyens@uhasselt.be 
Abstract

Although the use of the pesticide 2,2-bis(p-chlorophenyl)-1,1,1-trichloroethane (DDT) was banned from the mid-1970s, its most abundant and recalcitrant degradation product, 2,2-bis(p-chlorophenyl)1,1-dichloro-ethylene (DDE), is still present in terrestrial and aquatic ecosystems worldwide. Zucchini (Cucurbita pepo ssp. pepo) has been shown to accumulate high concentrations of DDE and was proposed for phytoremediation of contaminated soils. We performed a field trial covering a full plant life cycle. Cucurbita pepo plants inoculated with the plant growth-promoting endophytic strains Sphingomonas taxi UH1, Methylobacterium radiotolerans UH1, Enterobacter aerogenes UH1, or a consortium combining these three strains were grown on a DDE-contaminated field for 100 days. The effects of these inoculations were examined at both the plant level, by evaluating plant weight and plant DDE-content, and at the level of the cultivable and total endophytic communities. Inoculating plants with $S$. taxi $U H 1, M$. radiotolerans $U H 1$, and the consortium increased plant weight. No significant effects of the inoculations were observed on DDE-concentrations in plant tissues. However, the amount of DDE accumulated by C. pepo plants per growing season was significantly higher for plants that were inoculated with the consortium of the three strains. Therefore, inoculation of $C$. pepo with DDE-degrading endophytes might be promising for phytoremediation applications.

KEYWORDS: Pesticides, DDE, DDT, endophytes, field experiment 


\section{Introduction}

The pesticide 2,2-bis( $p$-chlorophenyl)-1,1,1-trichloroethane (DDT) was used worldwide until the 1970s when its deleterious effects on human health and wildlife were recognized ${ }^{1}$. In soils, DDT rapidly degrades to the persistent 2,2-bis(p-chlorophenyl)-1,1-dichloro-ethylene (DDE) and DDEcontaminated soils can still be found worldwide ${ }^{2,3}$. A possible remediation strategy for these contaminated soils is phytoremediation. Phytoremediation is an in situ natural remediation technology that has been demonstrated to be successful in many cases ${ }^{4-7}$. The strategy relies on plants and their associated microorganisms to take up contaminants from the soil and metabolize or store them ${ }^{8}$.

A primary requirement for the efficient phytoremediation of contaminated soils is an appropriate plant. Cucurbita pepo plants were shown to accumulate several organic contaminants under field conditions, including chlordane ${ }^{9}$, Dieldrin, Endrin ${ }^{10,11}$, and hexachlorocyclohexanes (HCHs) ${ }^{12,13}$. White et al. ${ }^{14}$ also demonstrated the effective uptake of weathered DDE by Cucurbita pepo ssp. pepo cultivar Raven. This zucchini cultivar showed soil-to-plant bioconcentration factors up to 23.7 and is thus a suitable plant for phytoremediation of DDE-contaminated soils.

However, when envisaging efficient phytoremediation, plants are not the sole factor. Endophytic bacteria that reside inside plant tissues are known to play crucial roles in plant growth and development in general ${ }^{15}$, as well as in the remediation of organic contaminants ${ }^{16}$.

A collection of 585 bacterial endophytic strains that was established during earlier research ${ }^{17}$ was investigated in vitro for plant growth-promoting traits and DDE-degradation potential. Suitable endophytes were selected and further identified through full genome sequencing ${ }^{18-20}$. After verifying the lack of pathogenic traits, the 3 full genome sequenced endophytic strains (Sphingomonas taxi UH1, Methylobacterium radiotolerans UH1, Enterobacter aerogenes UH1) were applied in the field experiment described in this manuscript. The main objectives of this experiment were to verify if the selected strains could promote both plant growth and DDE removal from a contaminated soil in situ. 
Materials and methods

\section{Inoculation of seeds}

The selected bacterial strains were cultivated by transferring $5 \mu \mathrm{L}$ of the bacterial stock into $30 \mathrm{~mL}$ of 869 medium (Mergeay et al., 1985). A consortium was created as well by combining the selected strains into one $50 \mathrm{~mL}$ tube. The bacterial suspensions were incubated at $30^{\circ} \mathrm{C}$ for 3 days.

Seeds of Cucurbita pepo ssp. pepo cultivar Raven (Johnny's Selected Seeds, Winslow, ME, USA) were surface sterilized for 1 minute in $1 \% \mathrm{NaOCl}$ and put in the bacterial suspension $\left(10^{9}\right.$ cells $\mathrm{mL}^{-}$ ${ }^{1}$ ) for overnight inoculation.

\section{Field characteristics}

The experimental field that was utilized for this trial is located on Lockwood Farm, owned by the Connecticut Agricultural Experiment Station (N41,406786 ${ }^{\circ}$ W72,906043; Hamden, CT, USA). The soil in the field was identified as being a Cheshire fine sandy loam soil containing $56 \%$ sand, $36 \%$ silt, and $8 \%$ clay. The percentage of organic carbon was 1.4 and an average pH of 6.7 was measured. The cation exchange capacity of the soil was $18.6 \mathrm{cmol} \mathrm{kg}^{-1}$.

\section{Growth and harvest of plants}

The seeds were germinated between wet paper towels for 3 days at $30^{\circ} \mathrm{C}$. The seedlings were transferred to $750 \mathrm{~mL}$ plastic pots containing vermiculite. The bacterial suspension was again added and plants watered daily with $1 / 4$ Hoagland nutrient solution ${ }^{21}$. After 7 days, the plants were of sufficient size to be transferred to the field. Plants were set out in 5 rows covered with black plastic to avoid weed growth. Each row containing 8 plants approximately $1 \mathrm{~m}$ apart (Figure 1). Holes were made in the plastic foil to insert the plants. Soil samples were taken from each mound/planting site to determine local DDE concentrations. The plants were watered continuously by a drip irrigation system underneath the plastic. 
Harvest ready fruits were collected 3 times per week. After a growing period of approximately 100 days, plants were harvested. Shoots were clipped and roots were excavated. All plant tissues were transferred to the lab for further analysis.

Weights were determined separately for leaves, stems, roots, and fruits. All plant tissues were rinsed thoroughly with tap water. Approximately $5 \mathrm{~g}$ of shoot and root tissue were separated for endophyte isolation and 454 pyrosequencing, while the remainder of plant tissues were homogenized and stored at $4^{\circ} \mathrm{C}$ for GCMS analysis to determine DDE concentrations.

\section{DDE content in plant tissues}

DDE was extracted from plant tissues using the QuEChERS method ${ }^{22}$. Up to $15 \mathrm{~g}$ fresh tissue was added to a $50 \mathrm{~mL}$ centrifuge tube with $15 \mathrm{~mL}$ acetonitrile and $30 \mu \mathrm{L}$ o,p'-DDE from a $10 \mathrm{mg} \mathrm{mL}^{-1}$ solution as an internal standard. The tubes were incubated on a wrist-action shaker for 10 min after which $6 \mathrm{~g} \mathrm{MgSO}_{4}$ and $1.5 \mathrm{~g} \mathrm{C}_{2} \mathrm{H}_{3} \mathrm{NaO}_{2}$ were added. The tubes were shaken for 30 min and afterwards centrifuged for $10 \mathrm{~min}$ at $3000 \mathrm{rpm}$. New $15 \mathrm{~mL}$ tubes were filled with $1.5 \mathrm{~g} \mathrm{MgSO}_{4}$ and $0.5 \mathrm{~g}$ of primary secondary amine (PSA). Two $\mathrm{mL}$ of toluene was added to wet the powders before $10 \mathrm{~mL}$ of the primary extract was transferred to each tube. The tubes were shaken for $30 \mathrm{~s}$ and centrifuged for $10 \mathrm{~min}$ at $3000 \mathrm{rpm}$. Six $\mathrm{mL}$ of each extract was concentrated to $1 \mathrm{~mL}$ under nitrogen pressure. These extracts were amended with $100 \mathrm{ng} \mathrm{mL}^{-1} o, p$ '-DDE as an internal standard before the DDE concentrations were determined using GCMS.

Standards of o,p'-DDE, p,p'-DDT, p,p'-DDD, and p,p'-DDE (Environmental Protection Agency National Pesticide Standard Repository, Fort Meade, MD) were weighed in toluene to prepare standards at $1,000 \mu \mathrm{g} \mathrm{mL} \mathrm{m}^{-1}$, which were then diluted to obtain mixed calibration standards from 25 $1,000 \mathrm{ng} \mathrm{mL} \mathrm{mL}^{-1}$. Each calibration was furthermore amended with $100 \mathrm{ng} \mathrm{mL}-1 \mathrm{o}, \mathrm{p}$-DDE as an internal standard since the breakdown of p,p'-DDT to p,p'-DDE/DDE in the GC inlet is unpredictable, total DDx was calculated. 
118 The concentration of DDx in plant tissues and soil was determined on an Agilent (Avondale, PA, 119 USA) 7890B gas chromatograph (GC) with a 5977A mass selective detector (MSD). Two microliters 120 of sample were injected into a multi-mode inlet (MMI) in pulsed splitless mode at $250^{\circ} \mathrm{C}$ with $\mathrm{He}$ as 121 the carrier gas and then onto an Agilent HP-5MS 30-m column with $0.25 \mathrm{~mm}$ ID and guard column. 122 The $\mathrm{GC}$ oven initial temperature was $150^{\circ} \mathrm{C}$ for $1 \mathrm{~min}$, then ramped to $250^{\circ} \mathrm{C}$ at a rate of $5^{\circ} \mathrm{C} \mathrm{min}^{-1}$, 123 and then ramped at a rate of $50^{\circ} \mathrm{C} \mathrm{min}^{-1}$ to a final temperature of $300^{\circ} \mathrm{C}$ which was held for $8 \mathrm{~min}$. 124 After a 5 min solvent delay, the MSD detected analytes using scan mode at a mass to charge ratio $125(\mathrm{~m} / \mathrm{z})$ 100-430. The instrument was calibrated with the standards described above, covering a range of $25-1,000 \mathrm{ng} \mathrm{mL}^{-1}$.

\section{Cultivation-dependent isolation}

Isolation of cultivable endophytes

130

131

132

At harvest, plant tissues were thoroughly washed with tap water in order to remove soil particles and plant weight was determined. Root and shoot tissues were incubated separately in $1 \% \mathrm{NaOCl}$ for surface sterilization. Subsequently, tissues were rinsed 3 times in sterile distilled water $\left(\mathrm{dH}_{2} \mathrm{O}\right)$ and dried on sterilized filter paper. In order to verify surface sterility, an aliquot (100 $\mu$ l) of the third rinsate was transferred to a Petri dish containing 869 medium ${ }^{23}$ (per liter: $0.35 \mathrm{~g} \mathrm{CaCl}_{2} .2 \mathrm{H}_{2} \mathrm{O}, 1.00 \mathrm{~g}$ Glucose D+, $5.00 \mathrm{~g} \mathrm{NaCl}, 10.0$ g Tryptone, $5.00 \mathrm{~g}$ Yeast Extract, $15 \mathrm{~g}$ Agar; adjusted to $\mathrm{pH} 7$ with $\mathrm{HCl}$ or $\mathrm{NaOH})$.

The surface sterilized tissues of three individual plants were transferred to sterilized mortars containing $5 \mathrm{~mL}$ sterile $10 \mathrm{mM} \mathrm{MgSO}_{4}$ and were crushed. The crushed root and shoot tissues were transferred to obtain serial dilutions $\left(0,10^{-1}, 10^{-2}, 10^{-3}, 10^{-4}\right)$ and each dilution $(100 \mu \mathrm{l})$ was spread onto plates containing $1 / 10$ diluted 869 medium ${ }^{23}$. All plates were prepared in triplicate and incubated at $30^{\circ} \mathrm{C}$ for 4 days. The colonies on the plates were counted and the number of colony forming units (cfu) per gram of fresh plant tissue were calculated. For each treatment, averages and standard errors 
were calculated of the 3 replicates. The colonies were purified and in total 585 isolated strains were stored in $15 \%$ w glycerol at $-80^{\circ} \mathrm{C}$.

\section{Genotypic characterization of cultivable bacterial strains}

The DNA of the 585 isolated strains was recovered with the Qiagen DNeasy blood and tissue kit (Qiagen, Venlo, the Netherlands). A Nanodrop ND-1000 Spectrophotometer (Isogen Life Science, De Meern, the Netherlands) was used to analyze the quality and quantity of the extracted DNA. The DNA was used directly for 16S rDNA amplification with a universal 1392R primer (5ACGGGCGGTGTGTRC-3) and a bacteria-specific $26 \mathrm{~F}$ primer (5AGAGTTTGATCCTGGCTCAG-3) ${ }^{24}$. The $16 \mathrm{~S}$ products were digested and separated by gel electrophoresis $(1.5 \%$ agarose, $90 \mathrm{~V}, 2 \mathrm{~h})$. The banding patterns were analyzed and 50 different DNA fingerprints were distinguished. At least one representative of each pattern was selected and sent for 16S rDNA sequencing at Macrogen (Amsterdam, the Netherlands). Consensus sequences were obtained with the Staden package and identification was acquired from the Ribosome Database Project based on the most closely related species (http://rdp.cme.msu.edu/classifier/classifier.jsp) ${ }^{25}$. The Shannon-Wiener indices of all different communities were calculated to estimate the diversity obtained after the different growth conditions ${ }^{26,27}$.

\section{Phenotypic characterization of cultivable bacterial strains}

The bacterial strains were tested in vitro for their plant growth-promoting traits. The bacteria were grown in liquid 869 medium ${ }^{23}$ at $30^{\circ} \mathrm{C}$ for 2 days, washed and resuspended in $1 \mathrm{~mL}$ sterile $\mathrm{MgSO}_{4}$. Twenty $\mu 1$ of this suspension was used for inoculation of 96 well microplate assays to investigate the production of IAA using Salkowski reagent ${ }^{28}$, siderophores using the Chrome Azurol S (CAS) assay 29, 1-aminocyclopropane-1-carboxylate (ACC) deaminase using 2,4-dinitrophenylhydrazine and $\mathrm{NaOH}^{30}$, organic acids using Alizarin red $\mathrm{S}^{31}$ and phosphate solubilization capacity using NBRIP 
medium ${ }^{32}$. For all plant growth promotion assays, the strains were assigned scores of + or depending on the presence of a color in the colorimetric tests.

\section{Screening bacteria for DDE-degrading capacities}

An auxanography test was performed for all bacterial strains to screen them for potential DDEdegradation capability. Each bacterial strain was grown in liquid 869 medium ${ }^{23}$. After 4 days, $1 \mu \mathrm{L}$ of each bacterial suspension was diluted in $999 \mu \mathrm{L}$ sterile $10 \mathrm{mM} \mathrm{MgSO}$.

One hundred $\mu \mathrm{l}$ of the bacterial suspension was plated on selective 284 medium. Immediately thereafter, $50 \mu \mathrm{L}$ of a sterile $50 \mathrm{mg} \mathrm{L}^{-1} \mathrm{DDE}$ or a $50 \mathrm{mg} \mathrm{L}^{-1} \mathrm{DDE}+200 \mu \mathrm{g}$-1 CuNPs solution were added to the surface and smeared out on $3 / 4$ of the outer circle of the plate (Figure 4 ). The plates were incubated at $30^{\circ}$ for 6 days. Plates with bacteria growing on the total surface were considered neutral, and were considered to be tolerant to the used concentrations of DDE and CuNPs. Plates on which strains did not show growth on the outer circle containing DDE and CuNPs were considered negative, since DDE was toxic to these bacterial strains. If the bacterial strains showed enhanced growth in the area covered with DDE, the plates were considered positive and these strains are presumed to use DDE as a carbon source while being tolerant to CuNPs.

\section{Statistical analysis}

The averages and standard deviations were calculated from three replicates from a mixed sample of three plants. The samples were compared using a one way ANOVA with Dunn comparison test.

\section{Cultivation-independent molecular analysis}

\section{Extraction and sequencing}

The plant tissue samples were surface sterilized (3 min in sterile MilliQ water, 1.5 min ethanol 70\%, 3 min $\mathrm{NaOCl} 1 \%, 1.5$ min ethanol 70\%, rinse 5 times in sterile MilliQ water) before being crushed in liquid nitrogen. All genomic DNA was extracted using an Invisorb spin plant mini kit (Stratec Biomedical, Germany). A template specific 967F primer (5- CAACGCGAAGAACCTTACC-3) was combined with 1391R primer (5- GACGGGCGGTGWGTRCA-3) to target a 424 bp fragment in the 
V3-V4 region. In a two-step PCR amplification, first the original primers were used, and then the same primers with a 10 bp multiplex identifier (MID) were employed. PCR reactions contained 1x Roche FastStart High Fidelity Reaction Buffer with $1.8 \mathrm{mM} \mathrm{MgCl}_{2}, 1.5 \mathrm{U}$ of Roche FastStart High Fidelity DNA-polymerase, 0.2 mM Roche dNTP, 300 nM 341F, 100 nM 783Ra, 100 nM 783Rb, 100 $\mathrm{nM} 783 \mathrm{Rc}$ and $1 \mu \mathrm{l}$ of $1 / 20$ diluted template DNA $\left(1 \mathrm{ng}^{\mathrm{l}} \mathrm{l}^{-1}\right)$ in a volume of $50 \mu \mathrm{l}$. The PCR program consisted of an initial denaturation step of $95^{\circ} \mathrm{C}$ for $2 \mathrm{~min}$, followed by 25 cycles $\left(1^{\text {st }} \mathrm{PCR}\right)$ or 10 cycles ( $2^{\text {nd }} \mathrm{PCR}$ ) of denaturation at $95^{\circ} \mathrm{C}$ for $30 \mathrm{~s}$, annealing at $53^{\circ} \mathrm{C}$ for $40 \mathrm{~s}$, extension at $72^{\circ} \mathrm{C}$ for 1 min, with a final extension of $5 \mathrm{~min}$ at $72^{\circ} \mathrm{C}$. The amplicons were purified from $1.5 \%$ agarose gels using a QIAquick gel extraction kit (Qiagen, Venlo, the Netherlands) and $1 \mu 1$ was used for the second PCR using MID-elongated primers. The PCR products were purified with a QIAquick PCR purification kit (Qiagen, Venlo, the Netherlands). The DNA was quantitated using a Quant-IT PicoGreen dsDNA assay kit (Life Technologies Europe, Gent, Belgium), after which equimolar concentrations of the barcoded amplicons were collected per library and diluted to $100 \mu \mathrm{l}$ using TE buffer. The library was unidirectionally sequenced using a Roche 454 GS-FLX Plus Life Sciences Genome Sequencer at Macrogen (Seoul, South Korea).

\section{Analysis of obtained pyrosequencing data}

The FASTA files containing the raw pyrosequencing data were accessed using Mothur bioinformatics software ${ }^{33}$ for processing and analysis according to Schloss et al. ${ }^{34}$. The obtained sequences were denoised before barcodes and primers were removed. The remaining sequences were aligned and classified along known sequences in the SILVA rRNA database ${ }^{35}$. Chimeric sequences, mitochondrial and chloroplast sequences were deleted and the remaining sequences were grouped into operational taxonomic units (OTUs) based on a 97\% similarity criterion. Rarefaction curves were starting to level off (Figure 5), but sequencing at a greater depth could have revealed more OTUs. The similarity between samples and their resemblance to the cultivated communities were visualized using Primer7 (Version 7.0.5, Primer-E Ltd.). Clustering of samples was based on S17 Bray-Curtis 
similarity of the group average of the species after square root transformation of the samples. The nMDS was based on S17 Bray-Curtis similarity as well, with square root transformation, Kruskall stress formula 1 and minimum stress 0.01. ANOSIM (analysis of similarities) with 999 permutations was used to test the spatial separation of the samples in nMDS.

\section{Results and discussion}

\section{Plant weights}

Plant weight was determined to evaluate the effects of inoculation with endophytic bacterial strains on plant growth over the total life cycle (Figure 2); the weights were determined separately for leaves, stems, roots, and fruits. Significant increases in weight were observed for stems and roots of plants inoculated with the consortium of all three strains. Furthermore, plants inoculated with $S$. taxi UHI and $M$. radiotolerans $U H 1$ showed tended to higher weights in comparison to non-inoculated control plants. However, plants inoculated with E. aerogenes UH1 showed a slightly diminished growth in comparison to controls; weights for leaves, stem, and roots tended to be lower. This generally improved weight underlines the plant growth-promoting effects of the endophytic strains.

\section{Soil DDE concentrations}

At the moment of planting, soil samples were taken from each mound to determine the soil DDE concentrations (table 1). No significant differences in soil DDE concentrations were observed. The plants from different treatments were randomly planted (Figure 1) for an optimal evaluation and comparison between the different inoculations.

\section{DDE concentrations in plant tissues}

After determining the DDE concentrations in different plant tissues (leaf, stem, root, and fruit), the bioconcentration factors (BCFs) could be calculated (Figure 3). The BCFs are the ratio of the concentration of DDE accumulated in the plant tissues to the concentration of DDE present in the soil. 
As expected, the BCFs of leaves are very low, ranging from 0.025 to 0.075 ; by comparison, BCFs of roots and stems range from 19 to 25 . This difference can be explained by the difficult translocation of DDE in plant tissues due to the hydrophobic character of the molecule. Therefore, larger effects of DDE on the endophytic communities can be expected in roots, in comparison to shoots.

With both the DDE concentrations of each plant compartment and weight of the respective compartments known, the total amount of DDE that was extracted from the field per plant during the entire growth period could be calculated as follows (Figure 4): (DDE concentration in plant tissue) $\mathrm{x}$ (plant weight).

Although no significant differences were observed between inoculated plants and control plants for the DDE concentrations, the total amount of DDE that was removed from the soil in one growth cycle was significantly higher in plants that were inoculated with the consortium in comparison to noninoculated control plants.

By estimating the mound volume in which a $C$. pepo plant can grow, the total amount of DDE a plant can reach was assessed. The mound had a surface area of $1 \mathrm{~m}$ by $0.5 \mathrm{~m}$ and a depth of $0.25 \mathrm{~m}$. This gives a volume of $125,000 \mathrm{~cm}^{3}$ with a density of $1.14 \mathrm{~g} \mathrm{~cm}^{-3}$, totaling $142.5 \mathrm{~kg}$ of soil per plant. Table 2 presents the amounts of DDE that were present per mound, the amounts of DDE that were taken up by the plants and the percentage this amount represents in comparison to the soil DDE content.

\section{Endophytic communities}

\section{Genotypic identification}

The endophytic communities of the roots and shoots were investigated using both cultivationdependent and cultivation-independent techniques. The cultivation-dependent isolation of the endophytic communities produced 530 cultivable strains, belonging to 4 phyla and 34 genera (Table 3 and Figure 6).

The cultivation-independent molecular analysis was conducted using 454 pyrosequencing. Macrogen (Seoul, South Korea) delivered the raw data in 4 FASTA files. These files contained in total 573,227 strains with a mean length of 388.01 base pairs. The files were analyzed using Mothur ${ }^{33}$ and the 
sequences were filtered using following criteria: length $>200 \mathrm{bp},<8$ homopolymers, $<2$ differences with the primers, $<1$ difference with the barcodes, pre-clustered to reduce sequencing errors, removal of chimeras, and more than $95 \%$ in the same range of genes. After this filtering, 207,128 sequences remained, containing a total of 26,862 unique sequences. Subsequently, all sequences belonging to mitochondria, chloroplasts, archaea, and eukaryotes were deleted. After this step, 199,500 sequences remained, implying that $3.66 \%$ of all sequences belonged to non-bacterial DNA. In the total of all samples, 288 different genera were detected belonging to 20 different phyla, or subphyla in case of the Proteobacteria (Figure 6). With a mean OTU length of $223.19 \mathrm{bp}$, identification to the species level was not possible.

Although 288 different genera were detected during the pyrosequencing process, many of them were only detected once across the different samples. Therefore, we focus on the 15 most abundant genera, which account for a large portion of the total bacterial communities (ranging from $64.83 \%$ to $79.66 \%$ of the total community).

Inoculating the plants with Sphingomonas taxi UH1, Methylobacterium radiotolerans UH1, Enterobacter aerogenes $U H 1$, or a consortium combining the three strains increased their abundancy in the community in the case of S. taxi UH1 (Shoot), M. radiotolerans UH1, E. aerogenes UH1 (Root) and the consortium but had no apparent effect on the presence of S. taxi UH1 (Root) and E. aerogenes UH1 (Shoot) since even a slightly lower presence was detected in the inoculated plants (Figure 7).

It is important to evaluate the inoculation efficiency since an inoculation can only be considered successful in case the presence of a bacterial strain is enhanced in the communities. However, in field conditions, an effective establishment of the inoculated strain is not evident because of the large number of bacterial genera competing for a position in the community.

The observed changes in abundance are larger for root communities of the plants inoculated with $M$. radiotolerans $U H 1$, E. aerogenes $U H 1$, and the consortium. This is not surprising since all three inoculated strains originated from roots of $C$. pepo plants exposed to DDE. 
Several authors mentioned that, when isolating endophytes, many bacterial genera are unaccounted for due to their inability to grow under laboratory conditions ${ }^{36,37}$. A comparison of the number of genera that are cultivable $(\mathrm{n}=34)$ and the number of genera present in the total bacterial communities $(n=288)$, seems to support this hypothesis. However, when comparing the percentages of the total bacterial communities that were recovered by the cultivation-dependent techniques, percentages ranging between $42.50 \%$ and $58.16 \%$ were observed at the genus level. This implies that although a significant part of the total communities was indeed cultivable under laboratory conditions, many endophytes that were present in the plant tissues were not cultivable.

When analyzing the similarity of all communities using the Analysis of Similarity (ANOSIM) and Similarity Percentages (SIMPER) tools in Primer7, a clear clustering by the cultivation-dependent and cultivation-independent techniques is observed (Figure 8). Due to the low cultivability rate of the endophytic communities, the cultivable-dependent techniques show a lower similarity than the cultivation-independent techniques that account for all endophytes present, $20.34 \%$ and $65.63 \%$ average similarity, respectively. The samples inoculated in different conditions also cluster inside the treatments, demonstrating the effect of inoculating the plants on the endophytic communities.

\section{Phenotypic identification}

Many endophytic bacterial strains were shown to possess plant growth-promoting capacities ${ }^{15}$. By investigating the symbiotic relationships between plants and their associated microorganisms, they might be exploited in phytoremediation processes ${ }^{16}$. Only cultivable endophytic strains can be tested for their plant growth-promoting capacities in vitro. Table 4 describes the percentages of bacteria that scored positive in the different plant growth promotion assays. Of the 530 strains that were examined, $2.83 \%(\mathrm{n}=15)$ showed no in vitro plant growth promotion in the 5 assays that were performed, while $4.34 \%(n=23)$ of all strains scored positive on all 5 assays. No differences were observed between the plant growth-promoting capacities of the endophytic communities isolated from non-inoculated control plants or from inoculated plants; the numbers of strains displaying in vitro plant growth promotion were very similar and apparently not influenced by inoculation. 
Along with their plant growth-promoting capacities, all strains were also assessed for their in vitro DDE-degradation potential (Table 5). A total of 39 strains or $7.36 \%$ showed DDE-degradation potential. Of these strains, 38 were isolated from plants that were previously inoculated with DDEdegrading endophytic strains, while the remaining strain was isolated from a non-inoculated control plant.

\section{Conclusion}

The effects of inoculating plants with Sphingomonas taxi UH1, Methylobacterium radiotolerans UH1, Enterobacter aerogenes UH1, or a consortium of all three strains were evaluated at different levels, plant growth, DDE-uptake, and endophytic communities.

Increasing tendencies were observed for the weight of plants inoculated with S. taxi UHI, M. radiotolerans $U H 1$, and the consortium in comparison to the non-inoculated control plants. The effect of inoculation with the consortium was significant for roots and stems. In contrast, inoculation with E. aerogenes $U H 1$ led to a slight, yet statistically insignificant decrease of the plant weight.

The DDE concentrations in the soil were similar for the different treatments (non-inoculated control or inoculated plants). Inoculation with DDE-degrading endophytes did not affect the bioconcentration factors of DDE in the plant tissues. The ratio of the concentrations of DDE inside the plant tissues to the DDE concentrations in the soil did not change when plants were inoculated.

However, when the amounts were calculated of DDE that was removed from the soils per plant and per growth cycle, a significantly higher value was observed for plants inoculated with the consortium of the three endophytic strains. This increase is mainly due to the higher root and stem weights of the plants, these being the compartments containing the highest DDE concentrations.

When the total and cultivable endophytic communities were evaluated and compared over all treatments, no obvious differences were observed. However, when comparing the abundances of the endophytic strains that were used for inoculation were compared between the non-inoculated control and the inoculated plants, increases were observed for S. taxi UH1 (shoot), M. radiotolerans UH1 (root and shoot), E. aerogenes UHI (root), and the consortium (root and shoot). However, the 
348 inoculated strains $S$. taxi $U H I$ and E. aerogenes $U H I$ were observed in slightly lower abundancies in 349 the shoot tissues of inoculated plants in comparison to the non-inoculated control plants. These 350 observations might be due to the fact that the endophytic strains were all originally isolated from roots 351 and thus predominantly or even exclusively colonized the roots of the inoculated plants.

352 When combining all these results, we can conclude that inoculation of Cucurbita pepo plants with a 353 consortium of Sphingomonas taxi UH1, Methylobacterium radiotolerans UH1, and Enterobacter 354 aerogenes $U H 1$ can significantly (46\%) increase the phytoremediation potential of the plants in DDE355 contaminated soils.

356

357 Acknowledgements

358 The financial support of the Flemish agency for Innovation by Science and Technology (IWT) for 359 project 121243 is greatly appreciated.

360

\section{Conflict of interest}

$362 \quad$ None declared 
TABLES

364 Table 1 Average DDE concentrations in soils at moment of planting

\begin{tabular}{ll}
\hline Treatment & $\begin{array}{l}\text { Average DDE concentration } \\
\text { (in } \mathbf{~ n g ~}^{-1} \mathbf{~ d r y ~ w e i g h t ) ~} \pm \mathbf{S D}\end{array}$ \\
\hline Non-inoculated control & $149.7 \pm 24.2$ \\
\hline Sphingomonas taxi UH1 radiotolerans & $153.0 \pm 34.8$ \\
\hline Methylobacterium & \\
UH1 & $147.0 \pm 24.0$ \\
\hline Enterobacter aerogenes UH1 & $158.6 \pm 50.1$ \\
\hline Consortium &
\end{tabular}

365 Control plants are not inoculated, other plants were inoculated with the indicated strains, or a 366 combination of the three strains for the consortium.

368 Table 2 Estimation of the amounts of DDE removed by C. pepo plants per mound during a full growth 369 cycle

\begin{tabular}{l|lllll}
\hline & Control & St & Mr & $\boldsymbol{E a}$ & Consortium \\
\hline $\begin{array}{l}\text { DDE concentration in } \\
\text { soil }\left(\mu \mathrm{g} \mathrm{kg}^{-1}\right)\end{array}$ & 149.65 & 172.76 & 153.02 & 146.96 & 178.60 \\
\hline $\begin{array}{l}\text { Amount of DDE per } \\
\text { mound (mg) }\end{array}$ & 21.667 & 25.012 & 22.154 & 21.277 & 25.858 \\
\hline $\begin{array}{l}\text { Amount of DDE taken } \\
\text { up by plant (mg) }\end{array}$ & 0.81010 & 0.95981 & 0.83243 & 0.71163 & 1.4132 \\
\hline $\begin{array}{l}\text { \% of DDE removed by } \\
\text { plant }\end{array}$ & 3.74 & 3.83 & 4.03 & 3.34 & 5.47 \\
\hline
\end{tabular}

371 Table 3 Cultivable bacterial genera isolated from Cucurbita pepo

\begin{tabular}{lll}
\hline Phylum & Class & Genus \\
\hline Actinobacteria & Actinobacteria & Arthrobacter \\
& $\begin{array}{l}\text { Curtobacterium } \\
\\
\end{array}$ & Frigoribacterium \\
\hline
\end{tabular}


Nocardioides

Plantibacter

Streptomyces

Terrabacter

\begin{tabular}{|c|c|c|}
\hline \multirow[t]{5}{*}{ Bacteriodetes } & \multirow[t]{3}{*}{ Flavobacteria } & Chryseobacterium \\
\hline & & Flavobacterium \\
\hline & & Myroides \\
\hline & \multirow[t]{2}{*}{ Sphingobacteria } & Chitinophaga \\
\hline & & Sphingobacterium \\
\hline \multirow[t]{18}{*}{ Proteobacteria } & \multirow[t]{8}{*}{ Alphaproteobacteria } & Agrobacterium \\
\hline & & Brevundimonas \\
\hline & & Devosia \\
\hline & & Ensifer \\
\hline & & Methylobacterium \\
\hline & & Ochrobactrum \\
\hline & & Rhizobium \\
\hline & & Sphingomonas \\
\hline & Betaproteobacteria & Variovorax \\
\hline & \multirow[t]{9}{*}{ Gammaproteobacteria } & Acinetobacter \\
\hline & & Enterobacter \\
\hline & & Klebsiella \\
\hline & & Lysobacter \\
\hline & & Pectobacterium \\
\hline & & Pseudomonas \\
\hline & & Stenotrophomonas \\
\hline & & Vibrio \\
\hline & & Xanthomonas \\
\hline \multirow[t]{2}{*}{ Firmicutes } & Bacilli & Bacillus \\
\hline & & Exiguobacterium \\
\hline
\end{tabular}

372 Bacterial genera (phylum, class) that were isolated from C. pepo using cultivation-dependent

373 techniques. 
375 Table 4 Percentages of bacterial strains showing plant growth-promoting capacities

\begin{tabular}{lllllll}
\cline { 3 - 7 } & & OA & IAA & Sid & ACC & P-sol \\
\hline Control & Root & $40 \%$ & $44 \%$ & $43 \%$ & $47 \%$ & $58 \%$ \\
\cline { 2 - 7 } & Shoot & $39 \%$ & $57 \%$ & $54 \%$ & $47 \%$ & $50 \%$ \\
\hline Inoculated & Root & $42 \%$ & $60 \%$ & $64 \%$ & $58 \%$ & $62 \%$ \\
\cline { 2 - 7 } & Shoot & $41 \%$ & $49 \%$ & $67 \%$ & $60 \%$ & $68 \%$
\end{tabular}

376 Plant growth-promoting capacities of tested bacterial strains (control $n=104$, inoculated $n=426$ ). OA $377=$ organic acids, IAA $=$ Indole- 3 -acetic acid, $\mathrm{Sid}=$ Siderophores, $\mathrm{ACC}=\mathrm{ACC}$-deaminase, $\mathrm{P}$-sol $=$ 378 phosphate solubilization.

380 Table 5 Bacterial strains showing DDE-degrading potential

\begin{tabular}{|c|c|c|}
\hline species & \# positive & Isolated from \\
\hline Arthrobacter sp. & 2 & $\mathrm{Ea}$ \\
\hline Chitinophaga sp. & 1 & $\mathrm{Ea}$ \\
\hline \multirow[t]{2}{*}{ Chryseobacterium sp. } & 1 & $\mathrm{St}$ \\
\hline & 2 & Control \\
\hline Enterobacter sp. & 1 & $\mathrm{Ea}$ \\
\hline Exiguobacterium sp. & 1 & Cons \\
\hline \multirow[t]{2}{*}{ Microbacterium sp. } & 2 & $\mathrm{Ea}$ \\
\hline & 2 & Control \\
\hline Pectobacterium sp. & 1 & $\mathrm{Ea}$ \\
\hline Plantibacter sp. & 3 & $\mathrm{Mr}$ \\
\hline \multirow[t]{2}{*}{ Pseudomonas sp. } & 2 & $\mathrm{Mr}$ \\
\hline & 3 & $\mathrm{Ea}$ \\
\hline \multirow[t]{2}{*}{ Rhizobium sp. } & 1 & Control \\
\hline & 1 & $\mathrm{Mr}$ \\
\hline \multirow[t]{3}{*}{ Sphingomonas sp. } & 2 & $\mathrm{Mr}$ \\
\hline & 1 & Control \\
\hline & 1 & $\mathrm{Ea}$ \\
\hline \multirow[t]{3}{*}{ Stenotrophomonas sp. } & 5 & Control \\
\hline & 2 & St \\
\hline & 2 & $\mathrm{Mr}$ \\
\hline
\end{tabular}




\begin{tabular}{lll}
\hline Variovorax sp. & 2 & Control \\
\hline Vibrio $s p$. & 1 & Cons
\end{tabular}

$381 \#$ positive $=$ number of bacterial strains that scored positive on the auxanography, Control $=$ not 382 inoculated, $\mathrm{St}=$ Sphingomonas taxi UH1, $\mathrm{Mr}=$ Methylobacterium radiotolerans $U H 1, \mathrm{Ea}=$ 383 Enterobacter aerogenes UH1, Cons = consortium. 


\section{FIGURE LEGENDS}

Figure 1 Layout of the field experiment. One meter of space was between each plant inside rows as well as in between rows. Each row was covered in black plastic and a watering system was present.

Figure 2 Average fresh weights \pm SD of Cucurbita pepo plants after harvesting in grams. St $=$ Sphingomonas taxi UH1, $\mathrm{Mr}=$ Methylobacterium radiotolerans $U H 1, \mathrm{Ea}=$ Enterobacter aerogenes $U H 1$, Cons = consortium, Red line indicates weight of control plants. a Leaf fresh weight, b Stem fresh weight, $\mathbf{c}$ Root fresh weight, $\mathbf{d}$ Fresh weight of all fruits harvested during the total growth period. * are significantly different from control plants, $\mathrm{p}<0.05$.

Figure 3 Bioconcentration Factors (BCFs) of different plant tissues (dry weight) from different treatments (average $\pm \mathrm{SD}) . \mathrm{BCF}=\mathrm{DDE}$ concentration in plant tissue/soil DDE concentration. $\mathrm{St}=$ Sphingomonas taxi UH1, $\mathrm{Mr}=$ Methylobacterium radiotolerans $U H 1, \mathrm{Ea}=$ Enterobacter aerogenes UH1, Cons = consortium.

Figure 4 Average amount of DDE (in $\mathrm{mg}$ ) removed \pm SD per plant per growth season in milligram for the different treatments. $\mathrm{St}=$ Sphingomonas taxi $U H 1, \mathrm{Mr}=$ Methylobacterium radiotolerans UH1, Ea = Enterobacter aerogenes UH1, Cons = consortium. $*$ is significantly different from noninoculated control plants $(\mathrm{p}<0.05)$.

Figure 5 Rarefaction curves of the different replicates and treatments of roots and shoots. The rarefaction curves were assembled showing the numbers of observed OTUs, defined at a $97 \%$ sequence similarity cut-off, relative to the total number of identified bacterial sequences.

Figure 6 Comparison of the compositions of the cultivable bacterial communities and the total bacterial communities for all treatments. Cultivable communities show all isolated species; total 
413 communities show the top 15 of detected species. Top: isolations from root material, bottom: 414 isolations from shoot material. $\mathrm{T}=$ Total community, $\mathrm{C}=$ Cultivable community, Control= non415 inoculated, $\mathrm{St}=$ inoculation with Sphingomonas taxi $\mathrm{UH1}, \mathrm{Mr}=$ inoculation with Methylobacterium 416 radiotolerans $U H 1, \mathrm{Ea}=$ inoculation with Enterobacter aerogenes $U H 1$, Consortium= inoculation 417 with the consortium of S. taxi UH1, M. radiotolerans UH1, and E. aerogenes UH1.

419 Figure $7 \%$ increase in the relative abundancy of the inoculated bacterial strains in comparison to the 420 endophytic communities of the control plants. St S: S. taxi UH1 Shoot, St R: S. taxi UH1 Root, Mr 421 S: M. radiotolerans UH1 Shoot, Mr R: M. radiotolerans UH1 Root, Ea S: E. aerogenes UH1 Shoot, 422 Ea R: E. aerogenes UH1 Root, Co S: Consortium Shoot, Co R: Consortium Root.

Figure 8 Cluster based on S17 Bray-Curtis similarity; cluster mode is the group average of the species 425 present in the samples; square root transformation; cophenetic correlation 0.94306 . Hollow circles= 426 cultivable community root tissue, hollow squares = cultivable community shoot tissue, full circles= 427 total community root tissue, full square $=$ total community shoot tissue. Blue $=$ control, green= 428 inoculated with $S$. taxi $U H 1$, red= inoculated with $M$. radiotolerans $U H 1$, purple= inoculated with $E$. 429 aerogenes $U H 1$, and orange= inoculated with a consortium of $S$. taxi UH1, M. radiotolerans UH1, 430 and E. aerogenes UHI. 
1. Turusov, V., Rakitsky, V. \& Tomatis, L. Dichlorodiphenyltrichloroethane (DDT): ubiquity,

persistence and risks. Environmental Health Perspectives 110, 125-128 (2002).

2. Thomas, J.E. \& Gohil, H. Microcosm studies on the degradation of $o, p^{\prime}-$ and $p, p^{\prime}-\mathrm{DDT}, \mathrm{DDE}$, and DDD in a muck soil. World Journal of Microbiology \& Biotechnology 27, 619-625 (2011).

3. Thomas, J.E., Ou, L. \& Al-Agely, A. DDE remediation and degradation. Reviews of Environmental Contamination and Toxicology 55-70 (2008).

4. Thijs, S. et al. Potential for plant growth promotion by a consortium of stress-tolerant 2,4dinitrotoluene-degrading bacteria: isolation and characterization of a military soil. Microbial Biotechnology 7, 294-306 (2014).

5. Vangronsveld, J. et al. Phytoremediation of contaminated soils and groundwater: lessons from the field. Environmental Science and Pollution Research 16, 765-794 (2009).

6. Weyens, $\mathrm{N}$. et al. Endophytic bacteria improve phytoremediation of $\mathrm{Ni}$ and TCE cocontamination. Environmental Pollution 158, 2422-2427 (2010).

7. Weyens, N., Van Der Lelie, D., Taghavi, S. \& Vangronsveld, J. Phytoremediation: plantendophyte parnterships take the challenge. Current Opinion in Biotechnology 20, 1-7 (2009).

8. McGuinness, M. \& Dowling, D. Plant-associated bacterial degradation of toxic organic compounds in soil. International Journal of Environmental Research and Public Health 6, 2226-2247 (2009).

9. Mattina, M.J.I., Lannucci-Berger, W., Musante, C. \& White, J.C. Concurrent plant uptake of heavy metals and persistent organic pollutants from soil. Environmental Pollution 124, 375378 (2003).

10. Matsumoto, E., Kawanaka, Y., Yun, S.J. \& Oyaizu, H. Bioremediation of the organochlorine pesticides, dieldrin and endrin, and their occurence in the environment. Applied Microbiology and Biotechnology 84, 205-216 (2009).

11. Otani, T., Seike, N. \& Sakata, Y. Differential uptake of dieldrin and endrin from soil by several plant families and Cucurbita genera. Soil science and plant nutrition 53, 86-94 (2007).

12. Bogdevich, O. \& Cadocinicov, O. in Application of phytotechnologies for cleanup of industrial, agricultural and wastewater contamination. (eds. P.A. Kulakow \& V.V. Pidlisnyuk) (Springer Science + Business Media B.V., 2010).

13. Moklyachuk, L., Gorodiska, I., Slobodenyuk, O. \& Petryshyna, V. in Application of phytotechnologies for cleanup of industrial, agricultural and wastewater contamination. (eds. P.A. Kulakow \& V.V. Pidlisnyuk) (Springer Science + Business Media B.V., 2010).

14. White, J.C. Inheritance of $p, p^{\prime}$-DDE phytoextraction ability in hybridized Cucurbita pepo cultivars. Environmental Science and Technology 44, 5165-5169 (2010).

15. Glick, B. Using soil bacteria to facilitate phytoremediation. Biotechnology Advances 28, 367374 (2010).

16. Weyens, N., Van Der Lelie, D., Taghavi, S., Newman, L. \& Vangronsveld, J. Exploiting plantmicrobe partnerships to improve biomass production and remediation. Trends in Biotechnology 10, 591-598 (2009).

17. Eevers, N., Hawthorne, J., White, J.C., Vangronsveld, J. \& Weyens, N. Exposure of Cucurbita pepo to DDE-contamination alters the endophytic community: A cultivation dependent vs a cultivation independent approach. Environmental Pollution 209, 147-154 (2016).

18. Eevers, N., Van Hamme, J.D., Bottos, E.M., Weyens, N. \& Vangronsveld, J., 3 e00317-00315 (Genome Announcements, 2015).

19. Eevers, N., Van Hamme, J.D., Bottos, E.M., Weyens, N. \& Vangronsveld, J. Draft genome sequence of Methylobacterium radiotolerans, a DDE-degrading and plant growth-promoting strain isolated from Cucurbita pepo. Genome Announcements 3, e00488-00415 (2015). 
20. Eevers, N., Van Hamme, J.D., Bottos, E.M., Weyens, N. \& Vangronsveld, J. Sphingomonas taxi, isolated from Cucurbita pepo, proves to be a DDE-degrading and plant growthpromoting strain. Genome Announcements 3, e00489-00415 (2015).

21. Hoagland, D.R. \& Arnon, D.I. The water-culture method for growing plants without soil, Vol. C347. (Berkely California: College of Agriculture, California; 1950).

22. De La Torre Roche, R. et al. Multiwalled carbon nanotubes and C-60 fullerenes differentially impact the accumulation of weathered pesticides in four agricultural plants. Environmental Science and Technology 47, 12539-12547 (2013).

23. Mergeay, M. et al. Alcaligenes entrophus $\mathrm{CH} 34$ is a facultative chemolitotroph with plasmidbound resistance to heavy metals. Journal of Bacteriology 162, 328-334 (1985).

24. Weyens, N. et al. Bacteria associated with oak and ash on a TCE-contaminated site: characterization of isolates with potential to avoid evapotranspiration. Environmental Science \& PollutionRresearch 16, 830-843 (2009).

25. Wang, Q., Garrity, G.M., Tiedje, J.M. \& Cole, J.R. Naive Bayesian classifier for rapid assignment of rRNA sequences into the new bacterial taxonomy. Applied and Environmental Microbiology 73, 5261-5267 (2007).

26. Keylock, C.J. Simpson diversity and the Shannon-Wiener index as special cases of a generalized entropy. Oikos 109, 203-207 (2005).

27. Spellerberg, I.F. \& Fedor, P.J. A tribute to Claude Shannon (1916-2001) and a plea for more rigorous use of species richness, species diversity and the 'Shannon-Wiener' Index. Global Ecology \& Biogeography 12, 177-179 (2003).

28. Patten, C. \& Glick, B. Role of pseudomonas putida indoleacetic acid in development of the host plant root system. Applied and Environmental Microbiology 68, 3795-3801 (2002).

29. Schwyn, B. \& Nielands, J.B. Universal chemical assay for the detection and determination of siderophores. Analytical Biochemistry 38, 209-222 (1961).

30. Belimov, A.A. et al. Cadmium-tolerant plant growth-promoting bacteria associated with the roots of Indian mustard. Soil Biology and Biochemistry 37, 247-250 (2005).

31. Cunningham, J.E. \& Kuiack, C. Production of citric and oxalic acids and solubilization of calcium phosphate by Penicillium bilaii. Applied Environmental Microbiology 58, 1451-1458 (1992).

32. Pikovskaya, R.I. Mobilization of phosphorus in soil in connection with vital activity of some microbial species. . Mikrobiologya 17, 362-370 (1948).

33. Schloss, P.D. et al. Introducing mothur: Open-source, plantform-independent, communitysupported software for describing and comparing microbial communities. Applied Environmental Microbiology 75, 7537-7541 (2009).

34. Schloss, P.D., Gevers, D. \& Westcott, S.L. Reducing the effects of PCR amplification and sequencing artefacts on 16S rRNA-based studies. PLoS One 6, e27310 (2011).

35. Pruesse, E. et al. SILVA: a comprehensive online resource for quality checked and aligned ribosomal RNA sequence data compatible with ARB. Nucleic Acids Research 35, 7188-7196 (2007).

36. Alain, K. \& Querellou, J. Cultivating the uncultured: limits, advances and future challenges. Extremophiles 13, 583-594 (2009).

37. Torsvik, V. \& Øvreås, L. Microbial diversity and function in soil: from genes to ecosystems. Current Opinion in Microbiology 5, 240-245 (2002). 


\section{$527 \quad$ Figure 4}

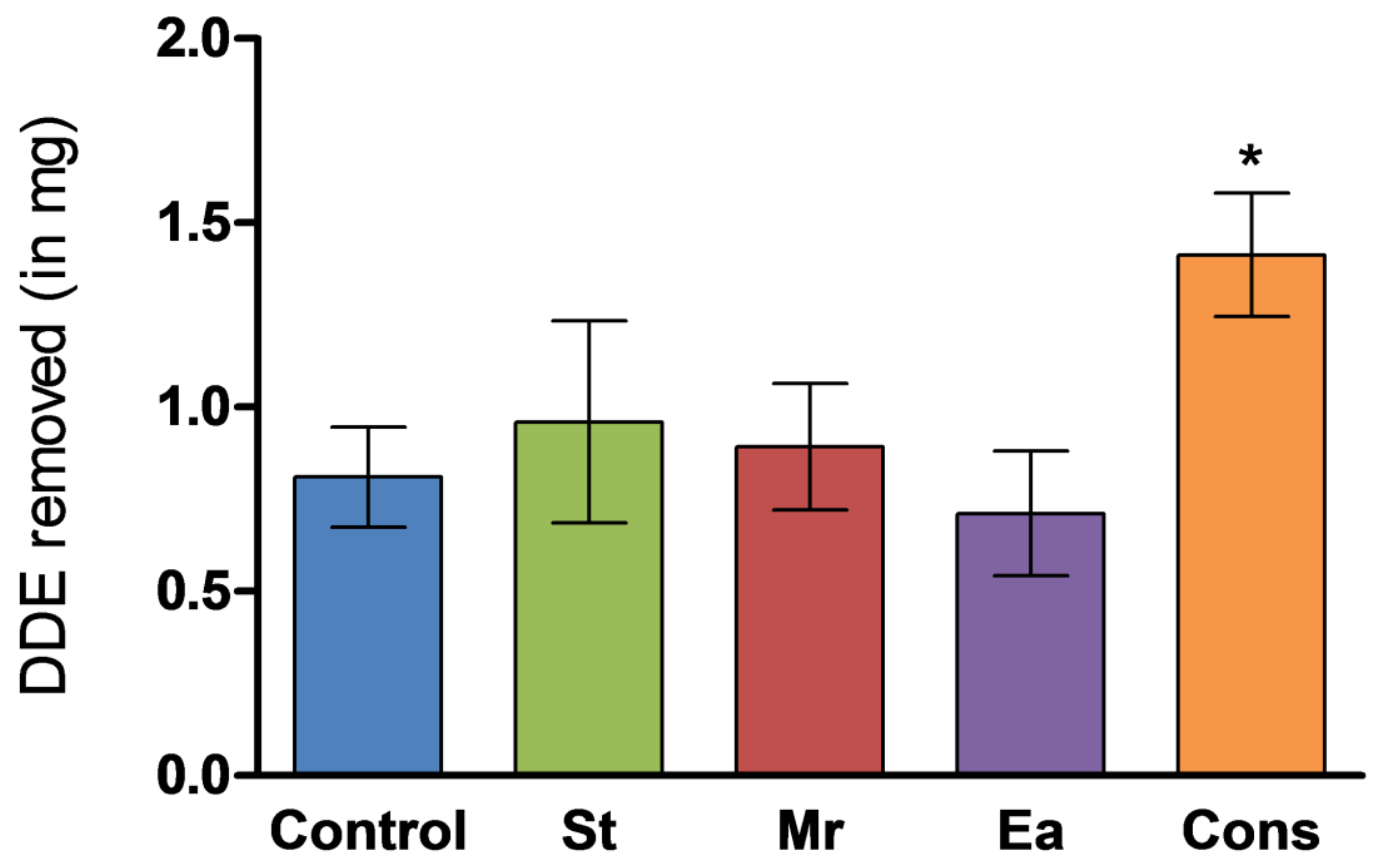

528

\section{$529 \quad \underline{\text { Figure } 5}$}

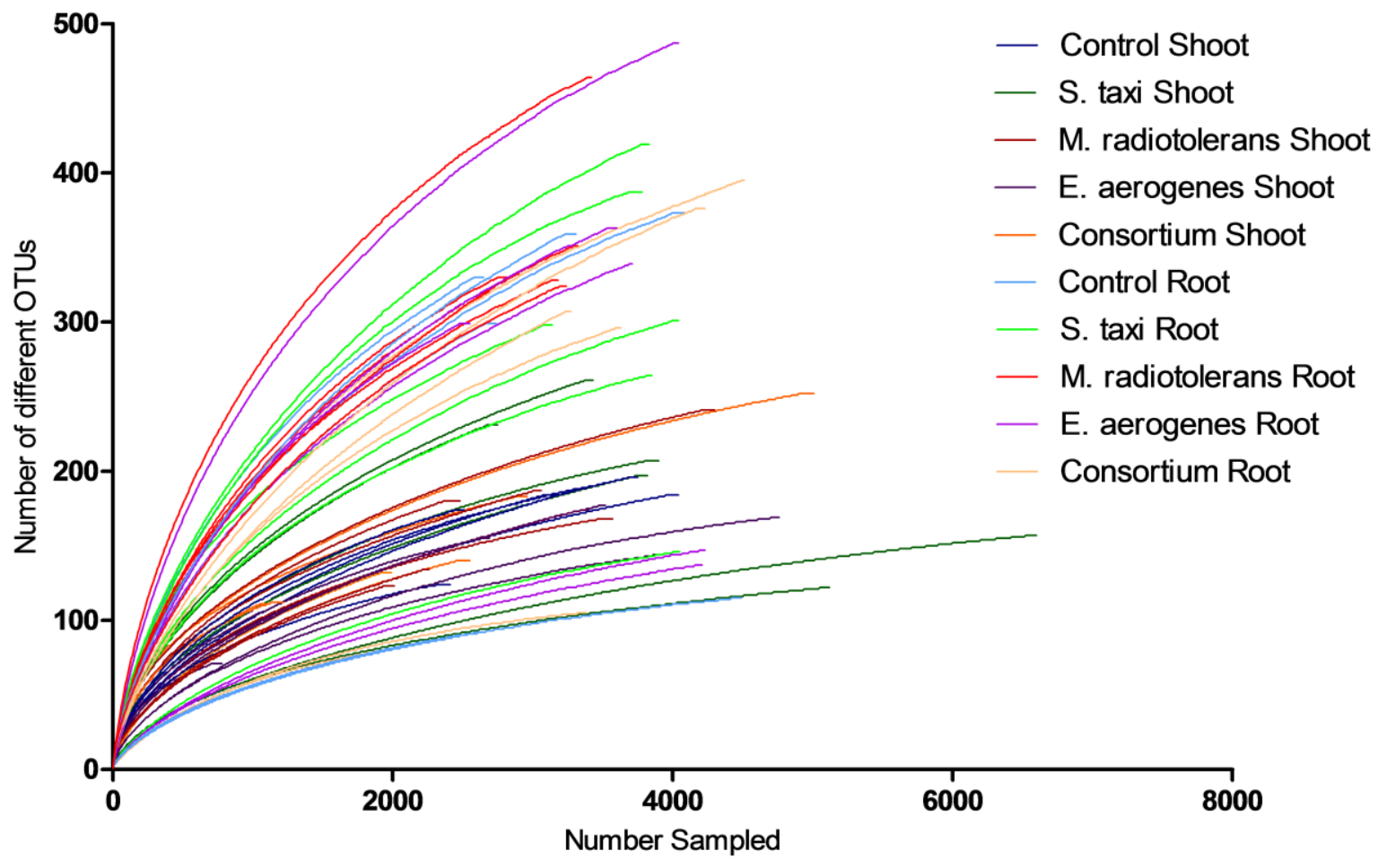




\section{Figure 6}

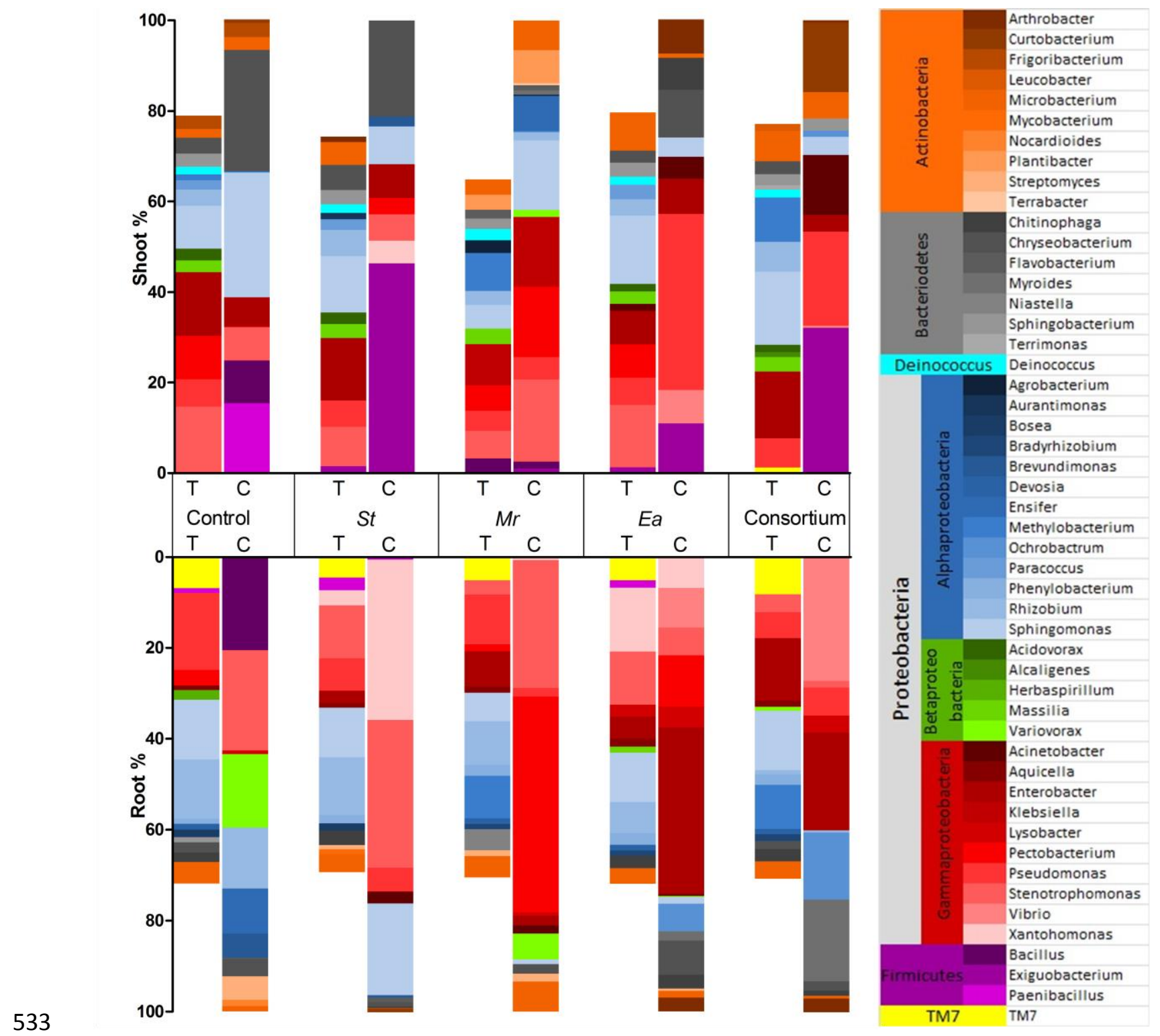

$534 \quad$ Figure 7 


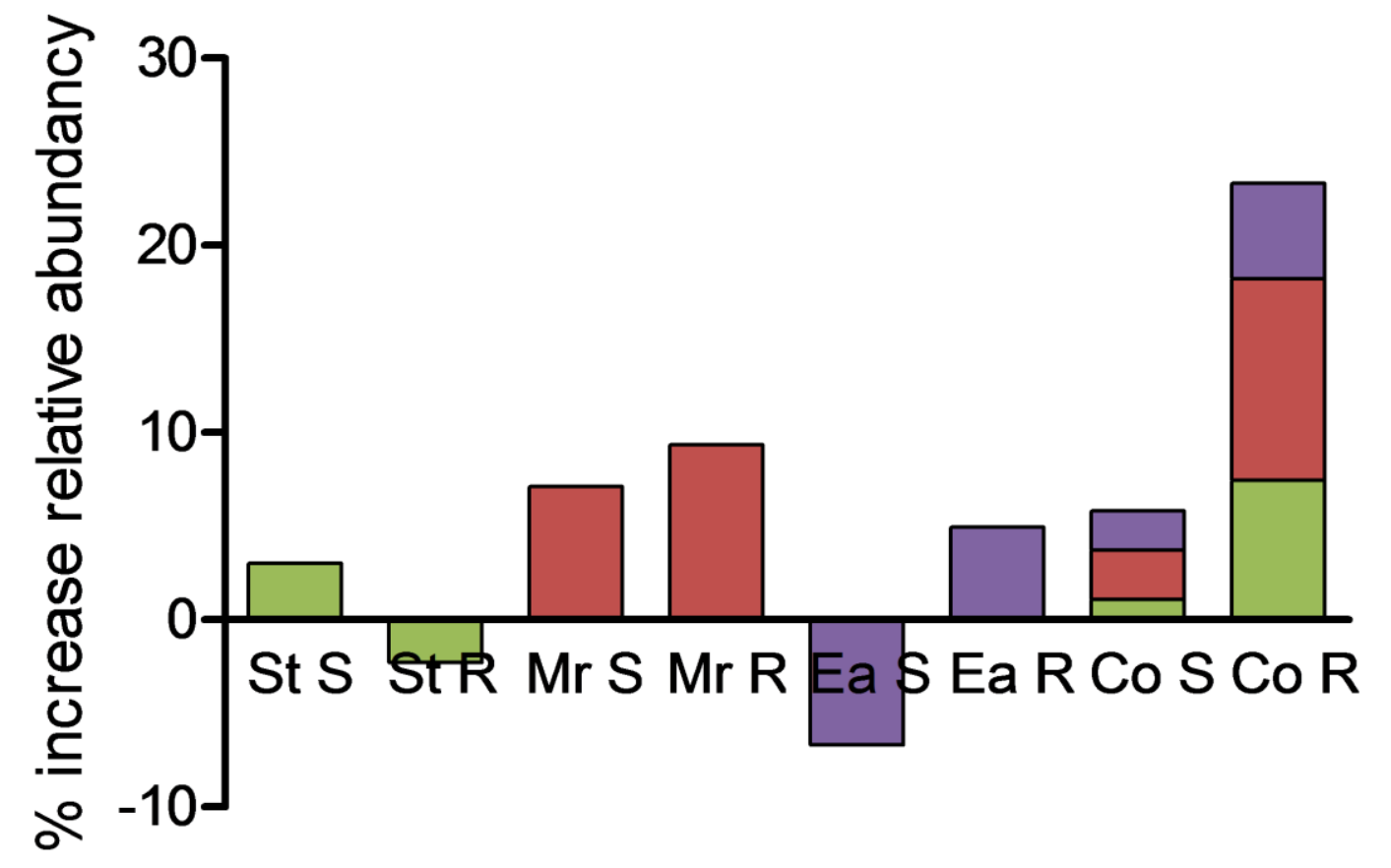

535

$536 \quad \underline{\text { Figure 8 }}$

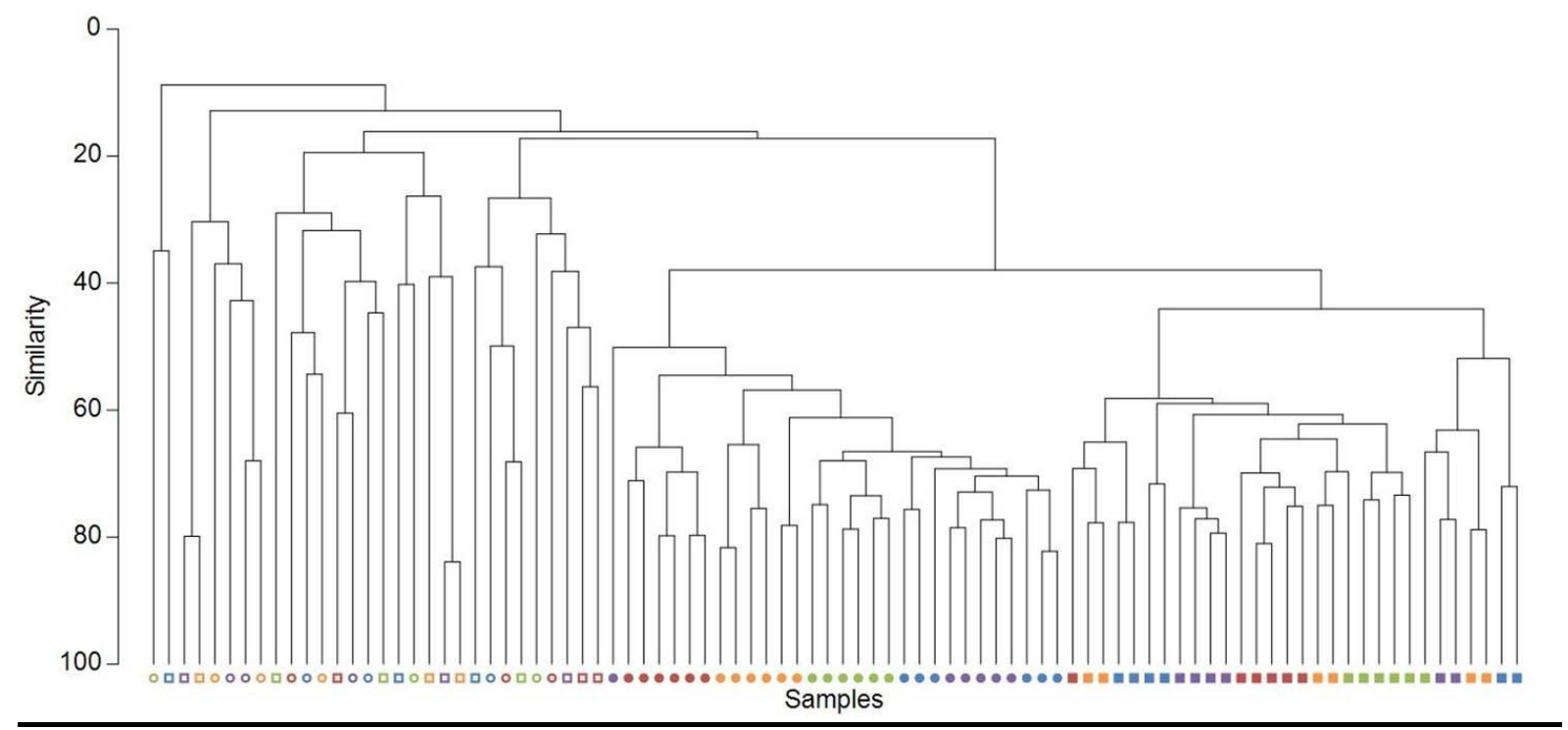

